\title{
Effect of intercostal nerve block combined with general anesthesia on the stress response in patients undergoing minimally invasive mitral valve surgery
}

\author{
YANPING ZHAN $^{1}$, GUO CHEN ${ }^{2}$, JIAN HUANG ${ }^{1}$, BENCHAO HOU ${ }^{1}$, WEICHENG LIU ${ }^{1}$ and SHIBIAO CHEN ${ }^{1}$ \\ ${ }^{1}$ Department of Anesthesia, The First Affiliated Hospital of Nanchang University, Nanchang, Jiangxi 330006; ${ }^{2}$ Department of \\ Reproductive Health, Jiangxi Province Maternal and Child Health Care Hospital, Nanchang, Jiangxi 330046, P.R. China
}

Received May 14, 2016; Accepted March 31, 2017

DOI: $10.3892 / \mathrm{etm} .2017 .4868$

\begin{abstract}
The aim of the present study was to investigate the effect of intercostal nerve block combined with general anesthesia on the stress response and postoperative recovery in patients undergoing minimally invasive mitral valve surgery (MIMVS). A total of 30 patients scheduled for MIMVS were randomly divided into two groups ( $\mathrm{n}=15$ each): Group $\mathrm{A}$, which received intercostal nerve block combined with general anesthesia and group B, which received general anesthesia alone. Intercostal nerve block in group A was performed with $0.5 \%$ ropivacaine from $\mathrm{T} 3$ to $\mathrm{T} 7$ prior to anesthesia induction. In each group, general anesthesia was induced using midazolam, sufentanil, propofol and vecuronium. Central venous blood samples were collected to determine the concentrations of cortisol, glucose, interleukin-6 (IL-6) and tumor necrosis factor- $\alpha$ (TNF- $\alpha)$ at the following time points: During central venous catheterization $\left(\mathrm{T}_{1}\right), 5 \mathrm{~min}$ prior to cardiopulmonary bypass $\left(T_{2}\right)$, perioperative $\left(T_{3}\right)$ and $24 \mathrm{~h}$ following surgery $\left(\mathrm{T}_{4}\right)$. Clinical data, including parameters of opioid (sufentanil) consumption, time of mechanical ventilation, duration of intensive care unit (ICU) stay, visual analog scale scores and any complications arising from intercostal nerve block, were recorded. Levels of cortisol, glucose, IL- 6 and TNF- $\alpha$ in group A were significantly lower than those in group B at $\mathrm{T}_{2}$ (all $\mathrm{P}<0.001$; cortisol, $\mathrm{P}<0.05$ ), $\mathrm{T}_{3}$ (all $\mathrm{P}<0.001$ ) and $\mathrm{T}_{4}$ (all $\mathrm{P}<0.001$; glucose, $\mathrm{P}<0.05$ ), suggesting that intercostal nerve block combined with general anesthesia may inhibit the stress response to MIMVS. Additionally, intercostal nerve block combined with general anesthesia may significantly reduce sufentanil consumption $(\mathrm{P}<0.001)$, promote early tracheal
\end{abstract}

Correspondence to: Dr Shibiao Chen, Department of Anesthesia, The First Affiliated Hospital of Nanchang University, 17 Yongwai Street, Nanchang, Jiangxi 330006, P.R. China

E-mail: chenshibiao2015@126.com

Key words: intercostal nerve block, general anesthesia, stress response, minimally invasive mitral valve surgery, postoperative analgesia extubation $(\mathrm{P}<0.001)$, shorten the duration of ICU stay $(\mathrm{P}<0.01)$ and attenuate postoperative pain $(\mathrm{P}<0.001)$, compared with general anesthesia alone. Thus, these results suggest that intercostal nerve block combined with general anesthesia conforms to the concept of rapid rehabilitation surgery and may be suitable for clinical practice.

\section{Introduction}

The stress response is a biological and psychological response caused by various stimuli including trauma, pain, blood loss and acute infection. It may lead to changes in the nervous, endocrine and immune systems, and alterations in metabolic processes and functions (1). Particularly when it is intense and persistent, the stress response may transform from an adaptive and protective role into a pathological phenomenon, and may even result in perioperative complications and mortality (2). Thus, a number of studies have attempted to alleviate stress damage, for example by afferent blocking of nociceptive stimulus or regulating humoral factors (3-5).

As a conventional path of cardiac surgery, median sternotomy carries the risk of severe surgical trauma, myocardial reperfusion injury, postoperative thoracic midline instability and blood loss (6). Thus, minimally invasive cardiac surgery has become widely used since its introduction $(7,8)$. Minimally invasive mitral valve surgery (MIMVS) may alleviate surgical trauma, shorten the duration of ICU stay, reduce blood loss and lower costs compared with median sternotomy $(7,8)$. However, a strong perioperative stress response still occurs following MIMVS, as do effects on different body systems due to incision, femoral artery and vein catheterization and hemodilution $(9,10)$. Thoracic epidural blockage and its contraindications, such as coagulation disorders, further limit the application of minimally invasive cardiac surgery $(9,10)$. The use of anesthesia is a potential method of improving operative conditions and regulating the stress response. Previous results indicate that combined anesthesia instead of single anesthesia may effectively relieve the stress response (11).

Compared with epidural block, intercostal nerve block exhibits lower risk of block failure, decreased discomfort for patients and broader application (12). In addition, intercostal nerve block produces more effective perioperative 
analgesia (13). To the best of our knowledge, the use of intercostal nerve block combined with general anesthesia in MIMVS has not been previously reported. Therefore, the current study was conducted to determine the effect of intercostal nerve block combined with general anesthesia on the stress response and postoperative recovery in patients undergoing MIMVS.

\section{Materials and methods}

Patients. Approval for the current study was provided by the Institutional Review Board of the First Affiliated Hospital of Nanchang University (Nanchang, China) for research and written informed consent was obtained from each patient. A total of 30 patients scheduled for MIMVS aged 31-53 years (12 males and 18 females) and hospitalized for rheumatic mitral stenosis in the First Affiliated Hospital of Nanchang University from October 2013 to March 2014 were recruited in the current study. Patients fit the American Society of Anesthesiologists (ASA) physical status II-III (14) and New York Heart Association status II-III (15), and were scheduled for surgery in the morning. Exclusion criteria were as follows: Diagnoses of metabolic or endocrine diseases (such as diabetes or thyroid disease), a history of chronic pain, alcohol abuse, analgesic drug medication, ventricular or atrial septal defect, patients who were not able to communicate verbally, previous internal jugular vein puncture under local anesthesia or intercostal nerve block, MIMVS performed in the afternoon or due to an emergency, and patients with a history of cardiac surgery and then undergoing further surgery.

Analgesia techniques. Patients were randomly divided into two groups ( $\mathrm{n}=15$ each): Group A receiving intercostal nerve block combined with general anesthesia and group B receiving general anesthesia alone. All patients underwent routine preoperative fasting for $12 \mathrm{~h}$ and were not permitted to drink for $6 \mathrm{~h}$. All patients received radial artery catheterization and central venous catheterization under local anesthesia with $1 \%$ lidocaine (Shanghai Fosun Zhaohui Pharmaceutical Co., Ltd., Shanghai, China). Those in group A received intercostal nerve block at the right side of the T3-T7 vertebrae and catheterization was placed in the posterior axillary line. Intercostal nerve block was induced with infusion of $3-5 \mathrm{ml} \mathrm{0.5 \%}$ ropivacaine (AstraZeneca AB, Södertalje, Sweden) on each intercostal space (T3-T7) when patients were in the supine position. To avoid systemic toxicity caused by local anesthetic and pneumothorax, procedures during block were performed in strict accordance with the aforementioned steps. Close observation of vital signs, communication and the mental status of patients were recorded. The block effect was assessed within 5-10 min of surgery to determine whether blocks were successful. The patient would be selected to induce general anesthesia if the block was successful, otherwise the case would have been excluded from group A. In group B, general anesthesia was induced in each patient.

General anesthesia was induced using $0.1 \mathrm{mg} / \mathrm{kg}$ midazolam (Jiangsu Nhwa Pharmaceutical Co., Ltd., Xuzhou, China), $1 \mu \mathrm{g} / \mathrm{kg}$ sufentanil (Yichang Renfu pharmaceutical Co., Ltd., Yichang, China), 1 mg/kg propofol (Qingyuan Jiabo Pharmaceutical Co., Ltd., Qingyuan, China) and $0.12 \mathrm{mg} / \mathrm{kg}$ vecuronium (Yangtze River Pharmaceutical Group Co., Ltd.,
Taizhou, China). A double-lumen endotracheal tube was used for tracheal intubation and the correct position of the tube was determined by auscultation of breath sounds. Mechanical ventilation and tidal volume $(8-10 \mathrm{ml} / \mathrm{kg})$ were regulated under a maintained respiratory rate (1:2) and end tidal $\mathrm{CO}_{2}$ $(35 \pm 5 \mathrm{mmHg})$. To maintain the bispectral index value at $\sim 50$, continuous infusion of $1-1.5 \mathrm{mg} / \mathrm{kg} / \mathrm{h}$ propofol and $0.04 \mathrm{mg} / \mathrm{kg}$ vecuronium was performed according to the anesthesia status and muscle relaxation. Subsequently, right intercostal muscle incision, left lung ventilation and respiratory parameter regulation were appropriately coordinated. When activated clotting time (ACT) was measured to reach 480 sec using a coagulation analyzer (Diagnostica Stago, S.A.S, Asnières-sur-Seine, France), anesthesia was deepened by increasing the amount of vecuronium (from 0.03 to $0.1 \mathrm{mg} / \mathrm{kg}$ ) and sufentanil (from 0.2 to $0.5 \mu \mathrm{g} / \mathrm{kg}$ ) according to the depth of anesthetic, and maintained by pumping propofol at a rate of $1-1.5 \mathrm{mg} / \mathrm{kg} / \mathrm{h}$ for cardiopulmonary bypass. Following surgery, whole lung ventilation, $1.5 \mu \mathrm{g} / \mathrm{kg} /$ day sufentanil infusion and intensive care unit (ICU) observation were performed for 16-22, 24-30 and 27-32 h, respectively. The visual analog scale (VAS) score (16) was recorded $24 \mathrm{~h}$ following surgery and the criteria were as follows: 0 (no pain), 1-2 (no pain at rest, mild pain with movement), 3-4 (mild pain at rest, moderate pain with movement or coughing), 5-6 (moderate pain at rest, severe pain with movement or coughing), 7-8 (severe pain at rest, acute pain with movement or coughing), 9-10 (acute pain at rest). Extubated time was recorded and cardiothoracic surgery ICU extubation criteria were as follows: Patient awake and cooperative, steady rhythm, inspiratory subpressure $>20 \mathrm{cmH}_{2} \mathrm{O}$, tidal volume $>10 \mathrm{ml} / \mathrm{kg}$, airway opening pressure $(\mathrm{Pao})>80 \mathrm{mmHg}$, fraction of inspired oxygen $\left(\mathrm{FIO}_{2}\right)<50 \%, \mathrm{pH}>7.30$, temperature $>36^{\circ} \mathrm{C}$, drainage volume $<100 \mathrm{ml} / \mathrm{h}$ for $2 \mathrm{~h}$. Cardiothoracic surgery ICU stay duration was recorded and patients were transferred out of the cardiothoracic surgery ICU if they met the following criteria: Patient awake and cooperative, steady cardiac rhythm, $\mathrm{FIO}_{2}<50 \%$, Pao $>80 \mathrm{mmHg}$, partial pressure of carbon dioxide $<60 \mathrm{mmHg}$, blood oxygen saturation $>90 \%$, drainage volume $<50 \mathrm{ml} / \mathrm{h}$ for $2 \mathrm{~h}$, urinary volume $>0.5 \mathrm{ml} / \mathrm{kg} / \mathrm{h}$.

Operation and cardiopulmonary bypass. The right parasternal approach was applied in mitral valve surgery. A 5-7 cm curved incision was made on the right anterolateral nipple and the pericardium was subsequently exposed through thoracotomy at T4. The pericardium was then vertically incised at $2 \mathrm{~cm}$ prior to the right phrenic nerve, and the heart and vessels were exposed between the aorta reflex and pericardial diaphragmatic surface. At T3 prior to the anterior axillary line, a $0.5 \mathrm{~cm}$ incision was made in order to secure the blocking clamp and another $0.5 \mathrm{~cm}$ incision was made to place the trocar with thoracoscopy. This provided a light source and expanded the surgical field. A $4 \mathrm{~cm}$ transverse incision at $2 \mathrm{~cm}$ below the inguinal ligament was used to expose the femoral artery and femoral vein. Tubes with heparin were then intubated in the artery and femoral vein. When ACT reached $480 \mathrm{sec}$ and the temperature dropped to $32-34^{\circ} \mathrm{C}$, the artery was transthoracically blocked. Subsequently, irrigated or inverse irrigated cardioplegia, mitral valve replacement, temperature recovery and aortic unclamping were carefully conducted. When the 
Table I. Comparison of patient characteristics.

\begin{tabular}{lcr}
\hline Characteristics & Group A & Group B \\
\hline Age (years) & $40.9 \pm 8.15$ & $42.4 \pm 9.99$ \\
Weight $(\mathrm{kg})$ & $55.0 \pm 5.58$ & $54.1 \pm 7.72$ \\
Gender (male/female) & $6 / 9$ & $6 / 9$ \\
American Society of Anesthesiologists class (II/III) & $8 / 7$ & $7 / 8$ \\
Duration of operation (min) & $235.1 \pm 5.17$ & $236.9 \pm 5.05$ \\
Duration of cardiopulmonary bypass (min) & $129.3 \pm 5.53$ & $128.2 \pm 4.09$ \\
Sufentanil administered $(\mu \mathrm{g} / \mathrm{kg})$ & $7.7 \pm 0.44^{\mathrm{a}}$ & $9.4 \pm 0.47$ \\
\hline
\end{tabular}

Data are presented as the mean \pm standard deviation unless stated otherwise. $n=15$. ${ }^{\mathrm{a}} \mathrm{P}<0.001$ vs. group $\mathrm{B}$.

heart pumped automatically, the atrium was closed. The tubes in the femoral vein and artery were removed following neutralization of heparin by protamine and the pericardium was sutured following epicardial hematischesis. Finally, a chest tube was placed and the chest was sutured layer by layer.

Sample collection and analysis. Central venous blood samples were collected in heparin tubes at four time points: $\mathrm{T}_{1}$ (at central venous catheterization), $\mathrm{T}_{2}$ (5 min before cardiopulmonary bypass), $\mathrm{T}_{3}$ (perioperative) and $\mathrm{T}_{4}(24 \mathrm{~h}$ after operation), and then centrifuged at 2,800 $\mathrm{x} g$ for $15 \mathrm{~min}$ at room temperature to obtain blood plasma. Blood glucose levels were determined using an ACCU-CHEK Blood Glucose Meter (Roche Diagnostics, Basel, Switzerland). Cortisol, interleukin (IL)- 6 and tumor necrosis factor (TNF)- $\alpha$ in the blood plasma derived from central venous blood at four time points were measured using Cortisol Radioimmunoassay (Ria) kit (catalogue no. HY-D0031), IL-6 Ria kit (catalogue no. HY-H0007), and TNF- $\alpha$ Ria kit (catalogue no. HY-H0019), respectively, according to their manufacturer's instructions (Beijing Sino-UK Institute of Biological Technology, Beijing, China). The amount of opioid analgesic drugs administered, extubation time, VAS score at $24 \mathrm{~h}$ after operation, duration of ICU stay and any intercostal nerve complications were recorded.

Statistical analysis. GraphPad Prism version 5.01 software (GraphPad Software, Inc., La Jolla, CA, USA) was used for all data analysis. Fisher's exact probability test was used to compare the differences between count data of the two groups. Measurement data were presented as the mean \pm standard deviation. Independent samples were compared using one-way analysis of variance (ANOVA) or Student's t-test. The independent sample t-test was used to assess differences between the two groups. Differences at each time point in the same group were analyzed using one-way ANOVA with Newman-Keuls post hoc test. $\mathrm{P}<0.05$ was considered to indicate a statistically significant difference.

\section{Results}

General conditions. Patient characteristics are presented in Table I. There were no significant differences in age, weight, gender or ASA class between the two groups of patients. All patients underwent successful surgery without experiencing any complications from anesthesia or surgical procedures. Sufentanil consumption was significantly reduced in group A compared with group $\mathrm{B}(\mathrm{P}<0.001)$, however no significant differences in the duration of operation or cardiopulmonary bypass were detected between the two groups (Table I).

Changes in blood glucose. Blood glucose levels in group A were significantly increased at $\mathrm{T}_{3}$ and $\mathrm{T}_{4}$ compared with at $\mathrm{T}_{1}(\mathrm{P}<0.001$; Fig. 1), however no significant difference was detected between $T_{1}$ and $T_{2}$ in group $A$. In group $B$, blood glucose levels were significantly increased at $T_{2}, T_{3}$ and $T_{4}$ compared with at $\mathrm{T}_{1}(\mathrm{P}<0.001)$. In each group, the maximum glucose level was reached at $\mathrm{T}_{3}$. Glucose levels in group $\mathrm{A}$ were significantly lower than those in group $\mathrm{B}$ at $\mathrm{T}_{2}(\mathrm{P}<0.001)$, $\mathrm{T}_{3}(\mathrm{P}<0.001)$ and $\mathrm{T}_{4}(\mathrm{P}<0.05$; Fig. 1).

Changes in plasma cortisol. Plasma cortisol levels in groups $A$ and $B$ were significantly increased at $\mathrm{T}_{3}$ and $\mathrm{T}_{4}$ compared with at $\mathrm{T}_{1}(\mathrm{P}<0.001 ;$ Fig. 2$)$ and reached a maximum at $\mathrm{T}_{3}$. The cortisol levels of group $\mathrm{A}$ at $\mathrm{T}_{2}$ were significantly lower than at $\mathrm{T}_{1}(\mathrm{P}<0.01)$. There were no significant differences in plasma cortisol levels between the two groups at $\mathrm{T}_{1}$, however the cortisol levels of group A were significantly lower than group $\mathrm{B}$ at $\mathrm{T}_{2}(\mathrm{P}<0.05), \mathrm{T}_{3}(\mathrm{P}<0.001)$ and $\mathrm{T}_{4}(\mathrm{P}<0.001$; Fig. 2).

Changes in plasma cytokine levels. Plasma levels of IL-6 in groups $\mathrm{A}$ and $\mathrm{B}$ were significantly increased at $\mathrm{T}_{2}, \mathrm{~T}_{3}$ and $\mathrm{T}_{4}$ compared with $\mathrm{T}_{1}$ (all $\mathrm{P}<0.001$; Fig. 3 ) and reached a maximum at $\mathrm{T}_{3}$. Plasma levels of TNF- $\alpha$ in groups $\mathrm{A}$ and $\mathrm{B}$ were significantly increased at $\mathrm{T}_{2}$ and $\mathrm{T}_{3}$ compared with at $\mathrm{T}_{1}($ all $\mathrm{P}<0.001)$ and reached a maximum at $\mathrm{T}_{3}$. The plasma level of TNF- $\alpha$ was significantly higher at $\mathrm{T}_{4}$ compared with $\mathrm{T}_{1}$ in group $\mathrm{B}$, however, in group $\mathrm{A}$, there was no significant difference in TNF- $\alpha$ levels between $T_{1}$ and $T_{4}$. There were no significant differences in the levels of IL- 6 and TNF- $\alpha$ between the two groups at $\mathrm{T}_{1}$, however levels of IL-6 and TNF- $\alpha$ were significantly lower in group A compared with group $\mathrm{B}$ at $\mathrm{T}_{2}, \mathrm{~T}_{3}$ and $\mathrm{T}_{4}$ (all $\mathrm{P}<0.001$; Fig. 3).

Complications of intercostal nerve block. Intercostal nerve blocks in 15 patients of group A were completed using $0.5 \%$ ropivacaine (AstraZeneca $\mathrm{AB}$ ) prior to general anesthesia 


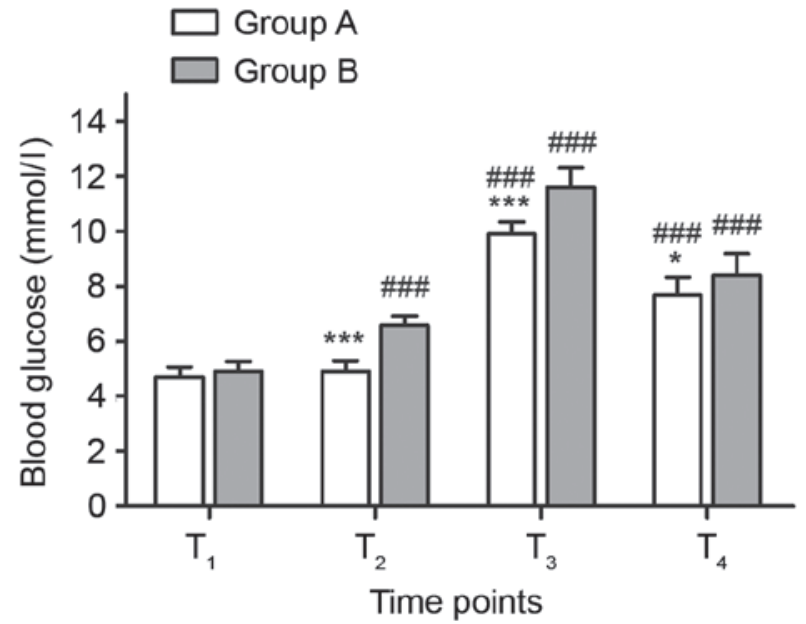

Figure 1. Comparison of blood glucose levels between groups A and B at different time points. $\mathrm{n}=15$. ${ }^{*} \mathrm{P}<0.05$ and ${ }^{* * * *} \mathrm{P}<0.001$ vs. group $\mathrm{B}$; ${ }^{\# \# *} \mathrm{P}<0.001$ vs. $T_{1} . T_{1}$, at central venous catheterization; $T_{2}, 5$ min before cardiopulmonary bypass; $\mathrm{T}_{3}$, perioperative; $\mathrm{T}_{4}, 24 \mathrm{~h}$ after operation.

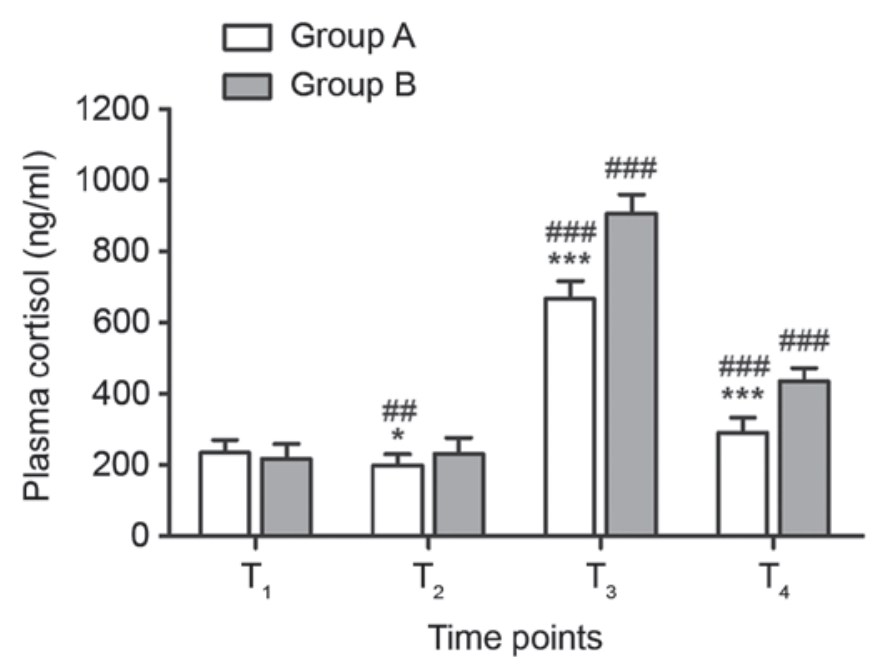

Figure 2. Comparison of plasma cortisol levels between groups $\mathrm{A}$ and $\mathrm{B}$. $\mathrm{n}=15 .{ }^{*} \mathrm{P}<0.05$ and ${ }^{* * * *} \mathrm{P}<0.001$ vs. group $\mathrm{B} ;{ }^{\# \#} \mathrm{P}<0.01$ and ${ }^{\# \#} \mathrm{P}<0.001$ vs. $\mathrm{T}_{1} . \mathrm{T}_{1}$, at central venous catheterization; $\mathrm{T}_{2}, 5 \mathrm{~min}$ before cardiopulmonary bypass; $\mathrm{T}_{3}$, perioperative; $\mathrm{T}_{4}, 24 \mathrm{~h}$ after operation.

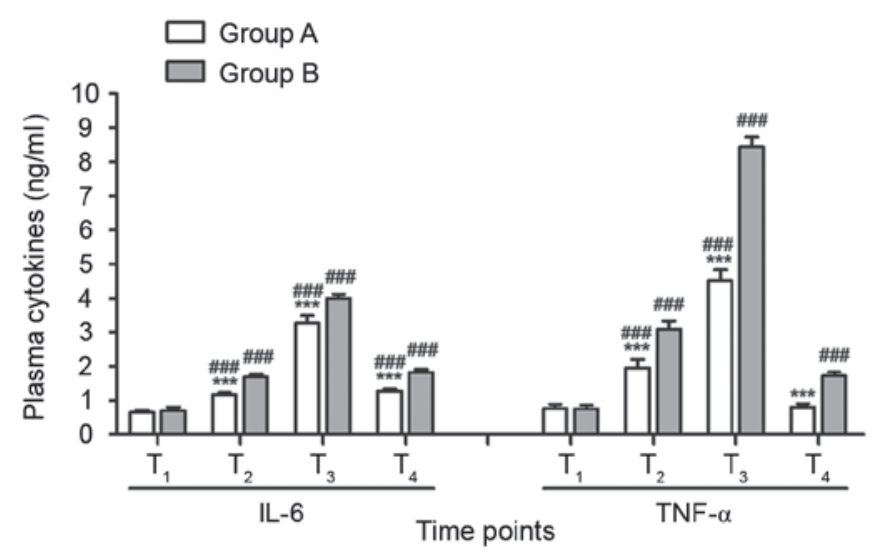

Figure 3. Comparison of postoperative recovery parameters between groups $\mathrm{A}$ and B. $\mathrm{n}=15 .{ }^{* * *} \mathrm{P}<0.001$ vs. group $\mathrm{B} ;{ }^{\# \# \#} \mathrm{P}<0.001$ vs. $\mathrm{T}_{1} . \mathrm{T}_{1}$, at central venous catheterization; $\mathrm{T}_{2}, 5$ min before cardiopulmonary bypass; $\mathrm{T}_{3}$, perioperative; $\mathrm{T}_{4}, 24 \mathrm{~h}$ after operation; IL, interleukin; $\mathrm{TNF}-\alpha$, tumor necrosis factor.
Table II. Comparison of postoperative recovery parameters ( $\mathrm{n}=15$ in each group).

\begin{tabular}{lrr}
\hline Parameter & Group A & \multicolumn{1}{c}{ Group B } \\
\hline Intensive care unit stay time (h) & $29.00 \pm 1.36^{\mathrm{a}}$ & $30.53 \pm 1.12$ \\
Extubation time (h) & $17.70 \pm 1.16^{\mathrm{b}}$ & $20.60 \pm 1.12$ \\
Postoperative 24 h visual & $3.70 \pm 0.59^{\mathrm{b}}$ & $5.30 \pm 0.60$ \\
analog scale score & & \\
\hline
\end{tabular}

Data are presented as the mean \pm standard deviation. ${ }^{\mathrm{a}} \mathrm{P}<0.01$ and ${ }^{\mathrm{b}} \mathrm{P}<0.001$ vs. group B.

when patients were awake. None of the patients experienced any complications including local anesthetic toxicity, pneumothorax or hemothorax.

Postoperative recovery. Compared with patients in group B, those in group A had significantly shorter extubation time $(\mathrm{P}<0.001)$, shorter ICU stays $(\mathrm{P}<0.01)$ and lower postoperative $24 \mathrm{~h}$ VAS scores $(\mathrm{P}<0.001$; Table II). These results may be due to the reduced dose of sufentanil in group A being beneficial to the implementation of fast-track anesthesia, a reduction in complications and early recovery of spontaneous breathing in patients.

\section{Discussion}

Surgical trauma may induce the stress response, which stimulates the production of many endogenous substances involved in perioperative myocardial ischemia $(17,18)$. The stress response may lead to a series of adverse effects such as the inhibition of organ function, a decline in immune function and metabolic enhancement $(17,18)$. It has been demonstrated that general anesthesia alone is unable to effectively suppress the surgical stress response (8). Wang and Lin (19) determined that the transmission of nociceptive nerve impulses and release of humoral factors from the injured tissue were the two key factors in stimulating the perioperative stress response. Thus, obstruction of these two pathways may be used to regulate the stress response. Ropivacaine, a novel amide-type local anesthetic agent, has been widely used clinically to induce nerve block and spinal canal anesthesia (20). In the present study, ropivacaine was used to induce intercostal nerve block in MIMVS, in order to reduce the surgical stress response.

When the stress response occurs, insulin attenuates the increase in catecholamine glucagon and glucocorticoid secretion, which promotes glycogen decomposition and increases cytokine release $(21,22)$. Cortisol, a glucocorticoid secreted by the adrenal cortex, is an important marker of the stress response. Plasma cortisol levels rapidly increase when nociceptive stimulation activates the hypothalamic-pituitary-adrenal cortex axis (23). IL- 6 and TNF- $\alpha$ are cytokines produced by monocytes and macrophages, and are important inflammatory mediators stimulated by the stress response in pathophysiological processes. Surgical trauma directly or indirectly leads to the increased biosynthesis and release of IL-6 (24). Levels of IL-6 are closely associated with the perioperative stimulus 
intensity and the degree of tissue damage (25). Furthermore, plasma TNF- $\alpha$ levels are positively correlated with the degree of the stress response and indicate the degree of damage in the body (26).

The current study investigated the effects of intercostal nerve block combined with general anesthesia (group A) compared with general anesthesia only (group B) on the perioperative stress response in MIMVS. Levels of cortisol, glucose, IL- 6 and TNF- $\alpha$ at $\mathrm{T}_{2}, \mathrm{~T}_{3}$ and $\mathrm{T}_{4}$ in group $\mathrm{A}$ were significantly lower than in group $\mathrm{B}$. This suggests that intercostal nerve block combined with general anesthesia more effectively reduces the perioperative stress response compared with general anesthesia alone. This may be due to the fact that local anesthetics block sensory nerve fibers and lead to the suspension of surgical noxious stimulation in central nervous conduction (27). General anesthesia may inhibit autonomic nervous system activity by inhibiting the limbic system of the cerebral cortex and the projection system of the cerebral cortex (11). Thus, the combined use of two types of anesthesia may inhibit the stress response in patients more effectively than the use of general anesthesia alone.

Blood glucose, cortisol, IL- 6 and TNF- $\alpha$ levels in the patients of group B were significantly elevated at $T_{2}, T_{3}$ and $\mathrm{T}_{4}$ compared with at $\mathrm{T}_{1}$ (with the exception of the cortisol level at $\mathrm{T}_{2}$, which did not differ significantly), and levels were also higher at $\mathrm{T}_{3}$ than at $\mathrm{T}_{2}$, which was consistent with previous results (26). In group A, blood glucose, cortisol, IL-6 and TNF- $\alpha$ concentrations at $\mathrm{T}_{3}$ were significantly higher compared with at $\mathrm{T}_{1}$, which may be due to the fact that the intercostal nerve block suppresses somatic nerve conduction but does not interfere with the transmission of visceral nociceptive signals to the central nervous system. This suggests that intercostal nerve block combined with general anesthesia may reduce but not completely block the stress response to MIMVS.

The T1-12 ventral ramus of spinal nerve located under the intercostal vessel and between the external and internal intercostal muscles is defined as the intercostal nerve (28). In the present study, ropivacaine, a long-acting local anesthetic that induces low cardiac and central nervous system toxicity and has a large dose range allowing it to be used safely, was used to block T3-T7 intercostal spaces $(29,30)$. Compared with bupivacaine, ropivacaine can block $\mathrm{A} \delta$ and $\mathrm{C}$ nerve fibers more effectively, has a faster onset time, has a longer blocking effect and induces greater sensory and motor block separation $(31,32)$. This may contribute to intercostal muscle movement function recovery and spontaneous breathing following early extubation. Local anesthetics must reach a minimum effective concentration $(\mathrm{Cm})$ to achieve satisfactory intercostal nerve block effects. D'Andrilli et al (33) demonstrated that $0.75 \%$ ropivacaine could achieve an analgesic effect for $48 \mathrm{~h}$ with a single intercostal nerve block, however in the current study only $0.5 \%$ ropivacaine was required to reach $\mathrm{Cm}$ and achieve a satisfactory nerve block.

A previous study demonstrated that the reduced dose of sufentanil was beneficial to the implementation of fast-track anesthesia, a reduction in complications including respiratory depression, nausea, vomiting and lethargy, and the early recovery of spontaneous breathing in patients with mild symptoms (34). In the present study, significantly lower sufentanil consumption, earlier tracheal extubation and a shorter ICU stay time were observed in group A compared with group B, and none of the patients in group A suffered any complications. The postoperative VAS score in group A was significantly lower compared with group B and effective postoperative analgesia was conducive to postoperative recovery in patients. this implied that the improvements in patients of group A may be due to the reduced dose of sufentanil.

In conclusion, intercostal nerve block combined with general anesthesia may inhibit the stress response to MIMVS, reduce sufentanil consumption, promote early tracheal extubation, shorten duration of ICU stay, attenuate postoperative pain, lessen complications and contribute to postoperative recovery in patients. The concept of rapid rehabilitation is based on reducing the surgical stress response of patients, surgical complications and mortality and promoting early recovery of patients, which was initially used in patients by Krohn et al (35). Therefore, intercostal nerve block conformed to the rapid rehabilitation surgery concept and may be suitable and beneficial in clinical practice.

\section{References}

1. Arfanis K, Fioratou E and Smith A: Safety culture in anaesthesiology: Basic concepts and practical application. Best Pract Res Clin Anaesthesiol 25: 229-238, 2011

2. Beilin B, Shavit Y, Trabekin E, Mordashev B, Mayburd E, Zeidel A and Bessler $\mathrm{H}$ : The effects of postoperative pain management on immune response to surgery. Anesth Analg 97: 822-827, 2003.

3. Rassias AJ and Procopio MA: Stress response and optimization of perioperative care. Dis Mon 49: 522-554, 2003.

4. Marrocco-Trischitta MM, Tiezzi A, Svampa MG, Bandiera G, Camilli S, Stillo F, Petasecca P, Sampogna F, Abeni D and Guerrini P: Perioperative stress response to carotid endarterectomy: The impact of anesthetic modality. J Vasc Surg 39: 1295-1304, 2004.

5. Tabuchi T, Shimazaki J, Satani T, Nakachi T, Watanabe Y and Tabuchi T: The perioperative granulocyte/lymphocyte ratio is a clinically relevant marker of surgical stress in patients with colorectal cancer. Cytokine 53: 243-248, 2011.

6. Kun $\mathrm{H}$ and Xiubin Y: Median sternotomy closure: Review and update research. J Med Coll PLA 24: 112-117, 2009.

7. Mack MJ: Minimally invasive cardiac surgery. Surg Endosc 20 (Suppl 2): S488-S492, 2006.

8. Laussen PC, Bichell DP, McGowan FX, Zurakowski D, DeMaso DR and del Nido PJ: Postoperative recovery in children after minimum versus full-length sternotomy. Ann Thorac Surg 69: 591-596, 2000.

9. Ho AM, Chung DC and Joynt GM: Neuraxial blockade and hematoma in cardiac surgery: Estimating the risk of a rare adverse event that has not (yet) occurred. Chest J 117: 551-555, 2000.

10. Waurick R and Van Aken H: Update in thoracic epidural anaesthesia. Best Pract Res Clin Anaesthesiol 19: 201-213, 2005.

11. Qu DM, Jin YF, Ye TH, Cui YS, Li SQ and Zhang ZY: The effects of general anesthesia combined with epidural anesthesia on the stress response in thoracic surgery. Zhonghua Yi Xue Za Zhi 83: 408-411, 2003 (In Chinese).

12. Detterbeck FC: Efficacy of methods of intercostal nerve blockade for pain relief after thoracotomy. Ann Thorac Surg 80: 1550-1559, 2005.

13. Taylor R, Massey S and Stuart-Smith K: Postoperative analgesia in video-assisted thoracoscopy: The role of intercostal blockade. J Cardiothorac Vasc Anesth 18: 317-321, 2004.

14. Owens WD, Felts JA and Spitznagel EL Jr: ASA physical status classifications: A study of consistency of ratings. Anesthesiology 49: 239-243, 1978.

15. Fisher JD: New York heart association classification. Arch intern med 129: 836, 1972.

16. Fredman B, Jedeikin R, Olsfanger D, Flor P and Gruzman A: Residual pneumoperitoneum: A cause of postoperative pain after laparoscopic cholecystectomy. Anesth Analg 79: 152-154, 1994. 
17. Gajarski RJ, Stefanelli CB, Graziano JN, Kaciroti N, Charpie JR and Vazquez D: Adrenocortical response in infants undergoing cardiac surgery with cardiopulmonary bypass and circulatory arrest. Pediatr Crit Care Me 11: 44-51, 2010.

18. Smith RC, Leung JM and Mangano DT: Postoperative myocardial ischemia in patients undergoing coronary artery bypass graft surgery. S.P.I. Research Group. Anesthesiology 74: 467-473 1991.

19. Wang HY and Lin CZ: Some proplems about perioperative stress response and its regulation. Int J Anesth Resusc 29: 173-176,184, 2008 (In Chinese).

20. Kopacz DJ, Emanuelsson BM, Thompson GE, Carpenter RL and Stephenson CA: Pharmacokinetics of ropivacaine and bupivacaine for bilateral intercostal blockade in healthy male volunteers. Anesthesiology 81: 1139-1148, 1994.

21. Robinson LE and Van Soeren MH: Insulin resistance and hyperglycemia in critical illness: Role of insulin in glycemic control AACN Clin Issues 15: 45-62, 2004.

22. Marik PE and Raghavan M: Stress-hyperglycemia, insulin and immunomodulation in sepsis. Intensive Care Med 30: 748-756, 2004.

23. Jung SM, Cho CK, Kim YJ, Cho HM, Kim CW, Kwon HU, Kim EK and Park JM: The effect of thoracic epidural anesthesia on pulmonary shunt fraction and arterial oxygenation during one-lung ventilation. J Cardiothorac Vasc Anesth 24: 456-462, 2010.

24. Helmy SA, Wahby MA and El-Nawaway M: The effect of anaesthesia and surgery on plasma cytokine production. Anaesthesia 54: 733-738, 1999

25. Kidd BL and Urban LA: Mechanisms of inflammatory Pain. Brit J Anaesth 87: 3-11, 2001.

26. Ozaktay AC, Cavanaugh JM, Asik L, DeLeo JA and Weinstein JN: Dorsal root sensitivity to interleukin-1 beta, interleukin- 6 and tumor necrosis factor in rats. Eur Spine J 11: 467-475; quiz $148-154,2002$.
27. Murauski JD and Gonzalez KR: Peripheral nerve blocks for postoperative analgesia. Aorn J 75: 136-147; quiz 148-154, 2002.

28. $\mathrm{Wu} \mathrm{ZD}$ and $\mathrm{Wu} \mathrm{ZH}$ : The 7th edition of Surgery [M]. Beijing: People's Health Publishing House, 2008.

29. Santos AC and DeArmas PI: Systemic toxicity of levobupivacaine, bupivacaine, and ropivacaine during continuous intravenous infusion to nonpregnant and pregnant ewes. Anesthesiology 95: 1256-1264, 2001

30. Graf BM, Abraham I, Eberbach N, Kunst G, Stowe DF and Martin E: Differences in cardiotoxicity of bupivacaine and ropivacaine are the result of physicochemical and stereoselective properties. Anesthesiology 96: 1427-1434, 2002.

31. Rofaeel A, El-Kharboutly W, Badran AEE and El-Sherif HA: Comparative evaluation of the efficacy of ropivacaine versus bupivacaine for continuous axillary brachial plexus block. Egypt J Anaesth 20: 405-410, 2004.

32. Cervero F and Laird JM: Understanding the signaling and transmission of visceral nociceptive events. J Neurobiol 61: 45-54, 2004.

33. D'Andrilli A, Ibrahim M, Ciccone AM, Venuta F, De Giacomo T, Massullo D, Pinto G and Rendina EA: Intrapleural intercostal nerve block associated with mini-thoracotomy improves pain control after major lung resection. Eur J Cardiothorac Surg 29: 790-794, 2006

34. Coluzzi F, Rocco A, Mandatori I and Mattia C: Non-analgesic effects of opioids: Opioid-induced nausea and vomiting: Mechanisms and strategies for their limitation. Curr Pharm Des 18: 6043-6052, 2012.

35. Krohn BG, Kay JH, Mendez MA, Zubiate P and Kay GL: Rapid sustained recovery after cardiac operations. J thorac cardiov sur 100: 194-197, 1990. 